\title{
OTIMIZAÇÃO, VALIDAÇÃO E APLICAÇÃO DE MÉTODO PARA DETERMINAÇÃO DA CONCENTRAÇÃO RESIDUAL DE DIFENOCONAZOL EM MORANGOS APÓS MÚLTIPLAS APLICAÇÕES
}

\author{
Fernanda Fernandes Heleno, Maria Eliana Lopes Ribeiro de Queiroz*, Antônio Augusto Neves e André Fernando de \\ Oliveira \\ Departamento de Química, Universidade Federal de Viçosa, 36570-000 Viçosa - MG, Brasil
}

Recebido em 24/04/2013; aceito em 01/08/2013; publicado na web em 10/09/2013

\begin{abstract}
OPTIMIZATION, VALIDATION AND APPLICATION OF A METHOD FOR DETERMINATION OF DIFENOCONAZOLE RESIDUES IN STRAWBERRIES AFTER MULTIPLE APPLICATIONS. Difenoconazole residues in strawberry fruit cultivated in pots were estimated using the solid-liquid extraction with low temperature partition (SLE/LTP) method for sample preparation and gas chromatography with electron capture detection (GC/ECD) for analysis. The optimized method presented excellent recovery values from fortified samples and reproducibility (average recovery values $\geq 98 \%$; $\mathrm{CV}$ values $\leq 15 \%$ ). Linearity of response was demonstrated $(\mathrm{r}=0.995)$ with a detection limit of $9 \mu \mathrm{g} \mathrm{kg}{ }^{-1}$. The method was successfully applied for the determination of difenoconazole residues in strawberries. Based on these results, the fungicide dissipates quickly, but the residual concentration increases after multiple applications.
\end{abstract}

Keywords: pesticide analysis; strawberry; gas chromatography.

\section{INTRODUÇÃO}

O difenoconazol (cis-trans-3-cloro-4-[4-metil-2-(1H-1,2,4triazol-1-ilmetil)-1,3-dioxolan-2-il]fenil 4-clorofenil eter) (Figura 1) é um fungicida sistêmico empregado no controle da mancha-de-mycosphaerella ou mancha-foliar causada pelo fungo Mycospharella fragariae. ${ }^{1}$ Esse princípio ativo é indicado para aplicação foliar em diferentes culturas, como maçã, uva, pimentão, tomate e morango.<smiles>CC1COC(Cn2cncn2)(c2ccc(Oc3ccc(Cl)cc3)cc2Cl)O1</smiles>

Figura 1. Estrutura química do difenoconazol

O uso indiscriminado de agrotóxicos e a não observância dos períodos de carência faz com que estes sejam detectados em concentrações acima do limite máximo de resíduo (LMR) em diversos alimentos. ${ }^{2}$ Nos alimentos consumidos in natura, como o morango, esse problema torna-se um pouco mais sério, uma vez que a população é exposta diretamente ao agrotóxico. O LMR de difenoconazol estabelecido pela Agência Nacional de Vigilância Sanitária (ANVISA) para essa cultura é de $500 \mu \mathrm{g}$ de princípio ativo por $\mathrm{kg}$ de morango. ${ }^{3}$

O morango, cada vez mais, vem se destacando por estar presente nos relatórios do Programa de Análises de Resíduos de Agrotóxicos em Alimentos (PARA) como um dos alimentos mais contaminados por resíduos de agrotóxicos no Brasil, por vários anos consecutivos. ${ }^{4}$

A extração do difenoconazol em matrizes vegetais geralmente é feita com solventes orgânicos seguida de uma etapa de clean-up em cartuchos de extração em fase sólida. ${ }^{5-7}$ Outra técnica que vem sendo empregada para determinação de resíduos de agrotóxicos em alimentos é a extração sólido-líquido com partição em baixa temperatura (ESL/PBT), que possui a vantagem de realizar simultaneamente as

*e-mail: meliana@ufv.br etapas de extração do analito e clean-up do extrato, além de baixo consumo de amostra e reagentes. ${ }^{8-10}$

O objetivo deste trabalho foi otimizar e validar o método de extração sólido-líquido com partição em baixa temperatura e análise por cromatografia gasosa com detector por captura de elétrons (ESL/ PBT-CG/DCE) para monitorar a concentração residual de difenoconazol em morangos que receberam múltiplas aplicações foliares desse princípio ativo.

\section{PARTE EXPERIMENTAL}

\section{Reagentes e soluções}

Os reagentes utilizados foram acetato de etila $(99,5 \% \mathrm{v} / \mathrm{v})$ e acetonitrila (99,5\% v/v) adquiridos da Vetec (Duque de Caxias, Brasil), e cloreto de sódio $(99,0 \% \mathrm{~m} / \mathrm{m})$ e ácido acético $(99,7 \%$ v/v) adquiridos da Isofar (Duque de Caxias, Brasil).

Solução padrão estoque de difenoconazol, na concentração de $1000,0 \mathrm{mg} \mathrm{L}^{-1}$, foi preparada pela solubilização do padrão de difenoconazol $(97,0 \% \mathrm{~m} / \mathrm{m})$ adquirido da Sigma-Aldrich (Steinheim, Alemanha) em acetonitrila. A solução de trabalho contendo o agrotóxico difenoconazol na concentração de $50,0 \mathrm{mg} \mathrm{L}^{-1}$ foi preparada a partir da diluição da solução padrão estoque com o mesmo solvente. Estas soluções foram armazenadas em freezer à temperatura de aproximadamente $-20{ }^{\circ} \mathrm{C}$.

\section{Preparo de amostras fortificadas}

Para a otimização e validação da técnica de extração sólido-líquido com partição em baixa temperatura (ESL/PBT) e análise por CG/DCE foram utilizados morangos isentos de agrotóxicos. Os morangos foram picados e triturados em mixer (Walita, São Paulo, Brasil) até total homogeneização. Em seguida, 4,0000 g (Balança Sartorius, Göettingen, Alemanha) de polpa foram colocados em frascos de vidro transparente com capacidade de $22,0 \mathrm{~mL}$, e fortificados com $80 \mu \mathrm{L}$ da solução de trabalho $\left(50,0 \mathrm{mg} \mathrm{L}^{-1}\right)$. Essas amostras de morango fortificadas foram deixadas em repouso por $3 \mathrm{~h}$ em recipiente aberto e posteriormente, submetidas ao método de ESL/PBT. 


\section{Condições cromatográficas}

Para determinação do analito de interesse foi empregado um cromatógrafo a gás (modelo GC-2014, Shimadzu, Kyoto, Japão) com detector por captura de elétrons (CG/DCE), equipado com autoinjetor AOC-20i. A temperatura do detector foi mantida em $300{ }^{\circ} \mathrm{C}$, o nitrogênio (99,999\%, Air Products, São Paulo, Brasil) foi empregado como gás de arraste e as injeções foram feitas com divisão de fluxo (split) de 1:5. As separações foram realizadas em uma coluna capilar DB-5 (Agilent Technologies, Palo Alto, EUA), com fase estacionária (5\%-fenil)-metilpolissiloxano, com $30 \mathrm{~m}$ de comprimento, $0,25 \mathrm{~mm}$ de diâmetro interno e $0,10 \mu \mathrm{m}$ de espessura de filme.

Para determinação de difenoconazol após extração por ESL/PBT foi empregada a seguinte programação de temperatura do forno da coluna: temperatura inicial de $200{ }^{\circ} \mathrm{C}$ com rampa de aquecimento de $20{ }^{\circ} \mathrm{C} \mathrm{min}{ }^{-1}$ até $290{ }^{\circ} \mathrm{C}$, sendo esta temperatura mantida por 4,5 min. A temperatura do injetor foi mantida em $280{ }^{\circ} \mathrm{C}$ e o fluxo do gás de arraste empregado foi de $1,2 \mathrm{~mL} \mathrm{~min}^{-1}$. O volume injetado foi de $1,0 \mu \mathrm{L}$ e o tempo total de análise foi de $9 \mathrm{~min}$. As corridas foram gerenciadas pelo software GCsolution (Shimadzu, Kyoto, Japão).

O difenoconazol foi identificado por comparação do tempo de retenção do pico presente nos extratos das amostras com o tempo de retenção do padrão. A quantificação foi feita empregando o método de superposição de matriz. ${ }^{11}$

\section{Otimização da técnica de extração sólido-líquido com partição em baixa temperatura (ESL/PBT)}

A otimização da técnica de extração sólido-líquido com partição em baixa temperatura (ESL/PBT) para análise de difenoconazol em amostras de morango foi adaptada das técnicas de extração de agrotóxicos em leite e tomate. ${ }^{9,12}$

Nesta técnica 4,0000 g de polpa de morangos foram colocados em contato com a solução extratora. Após agitação e centrifugação, a mistura foi deixada em freezer a $-20{ }^{\circ} \mathrm{C}$ para separação das fases pelo congelamento da polpa. O extrato orgânico foi analisado por CG/DCE.

A técnica foi otimizada de forma multivariada em que os parâmetros: tipo de solução extratora, razão massa de amostra:volume de solução extratora e tempos de agitação, centrifugação e refrigeração foram avaliados. Um planejamento fatorial completo e um planejamento composto central foram utilizados para a otimização desses parâmetros.

\section{Planejamento fatorial completo}

Foi empregado um planejamento fatorial completo $2^{2}$ para avaliação do comportamento simultâneo dos fatores tipo de solução extratora e razão massa de amostra:volume de solução extratora, em dois níveis. As análises foram realizadas em duplicata e os dados do planejamento são mostrados na Tabela 1 .

As melhores condições dos planejamentos foram avaliadas em função das respostas cromatográficas (áreas) obtidas em cada ensaio. Esses dados foram analisados empregando o software Statistica (versão 8, StatSoft Corp., Tulsa, EUA).

\section{Planejamento composto central}

Na otimização do processo de extração, os tempos de agitação em mesa agitadora (Tecnal - modelo TE 420, Piracicaba, Brasil) a 200 rpm, de centrifugação (Centrífuga Excelsa II, modelo 206MP, FANEM, São Paulo, Brasil) a 560 g e o tempo de partição a baixa temperatura no freezer (Consul, modelo 280, São Paulo, Brasil) a $-20{ }^{\circ} \mathrm{C}$ foram avaliados por um planejamento composto central. $\mathrm{O}$ planejamento empregado foi o fatorial $2^{3} \mathrm{com}$ cinco pontos centrais e extensão axial, totalizando 19 ensaios (Tabela 2).
Tabela 1. Planejamento fatorial $2^{2}$, em duplicata, realizado para estabelecer as melhores condições para extração de difenoconazol de amostras de morango

\begin{tabular}{ccccc}
\hline \multirow{2}{*}{ Ensaio } & \multicolumn{2}{c}{ Fatores (Valores Codificados) } & \multicolumn{2}{c}{ Fatores (Valores Reais) } \\
\cline { 2 - 5 } & SE & A/SE & SE & A/SE \\
\hline 1 & - & - & ACN & $4,0 \mathrm{~g}: 4,0 \mathrm{~mL}$ \\
2 & + & - & ACN/ACE & $4,0 \mathrm{~g}: 4,0 \mathrm{~mL}$ \\
3 & - & + & ACN & $4,0 \mathrm{~g}: 8,0 \mathrm{~mL}$ \\
4 & + & + & ACN/ACE & $4,0 \mathrm{~g}: 8,0 \mathrm{~mL}$ \\
5 & - & - & ACN & $4,0 \mathrm{~g}: 4,0 \mathrm{~mL}$ \\
6 & + & - & ACN/ACE & $4,0 \mathrm{~g}: 4,0 \mathrm{~mL}$ \\
7 & - & + & ACN & $4,0 \mathrm{~g} / 8,0 \mathrm{~mL}$ \\
8 & + & + & ACN/ACE & $4,0 \mathrm{~g}: 8,0 \mathrm{~mL}$ \\
\hline
\end{tabular}

$\mathrm{A}=$ amostra; $\mathrm{SE}=$ solução extratora; $\mathrm{ACN}=$ acetonitrila; $\mathrm{ACE}=$ acetato de etila; $\mathrm{ACN} / \mathrm{ACE}=$ mistura dos dois solventes na proporção $81,25: 18,75 \mathrm{v} / \mathrm{v}$.

Tabela 2. Planejamento composto central realizado para estabelecer as melhores condições para extração de difenoconazol de amostras de morango

\begin{tabular}{|c|c|c|c|c|c|c|}
\hline \multirow{2}{*}{ Ensaio } & \multicolumn{3}{|c|}{ Fatores (Valores Codificados) } & \multicolumn{3}{|c|}{ Fatores (Valores Reais) } \\
\hline & A & $\mathrm{C}$ & $\mathrm{R}$ & $\mathrm{A}(\mathrm{min})$ & $\mathrm{C}(\mathrm{min})$ & $\mathrm{R}(\mathrm{h})$ \\
\hline 1 & - & - & - & 10,0 & 3,0 & 5,0 \\
\hline 2 & - & - & + & 10,0 & 3,0 & 12,0 \\
\hline 3 & - & + & - & 10,0 & 5,0 & 5,0 \\
\hline 4 & - & + & + & 10,0 & 5,0 & 12,0 \\
\hline 5 & + & - & - & 20,0 & 3,0 & 5,0 \\
\hline 6 & + & - & + & 20,0 & 3,0 & 12,0 \\
\hline 7 & + & + & - & 20,00 & 5,00 & 5,00 \\
\hline 8 & + & + & + & 20,0 & 5,0 & 12,0 \\
\hline 9 & $-\alpha$ & 0 & 0 & 6,6 & 4,0 & 8,5 \\
\hline 10 & $\alpha$ & 0 & 0 & 23,4 & 4,0 & 8,5 \\
\hline 11 & 0 & $-\alpha$ & 0 & 15,0 & 2,3 & 8,5 \\
\hline 12 & 0 & $\alpha$ & 0 & 15,0 & 5,7 & 8,5 \\
\hline 13 & 0 & 0 & $-\alpha$ & 15,0 & 4,0 & 2,6 \\
\hline 14 & 0 & 0 & $\alpha$ & 15,0 & 4,0 & 14,4 \\
\hline $15 \mathrm{C}$ & 0 & 0 & 0 & 15,0 & 4,0 & 8,5 \\
\hline $16 \mathrm{C}$ & 0 & 0 & 0 & 15,0 & 4,0 & 8,5 \\
\hline $17 \mathrm{C}$ & 0 & 0 & 0 & 15,0 & 4,0 & 8,5 \\
\hline $18 \mathrm{C}$ & 0 & 0 & 0 & 15,0 & 4,0 & 8,5 \\
\hline $19 \mathrm{C}$ & 0 & 0 & 0 & 15,0 & 4,0 & 8,5 \\
\hline
\end{tabular}

$\mathrm{A}=$ tempo de agitação; $\mathrm{C}=$ tempo de centrifugação; $\mathrm{R}=$ tempo de refrigeração.

\section{Figuras de mérito do procedimento analítico}

A linearidade foi avaliada pela curva analítica obtida pela análise dos extratos de amostras fortificadas com concentrações de difenoconazol que variaram de $250-1000 \mu \mathrm{g} \mathrm{kg}^{-1}(\mathrm{n}=42$, sete pontos em triplicata e uma reinjeção). A relação matemática entre o sinal (resposta) e a concentração do analito de interesse foi expressa pela equação da curva analítica e o seu coeficiente de correlação (r). Os parâmetros de desempenho avaliados para o método foram: seletividade, precisão (repetitividade e precisão intermediária), exatidão/recuperação, limite de detecção (LD) e limite de quantificação (LQ) do analito.

Os limites de detecção e quantificação foram calculados pela 
relação entre a estimativa do desvio padrão do coeficiente linear e a inclinação da curva analítica. $\mathrm{O}$ valor resultante foi multiplicado por 3,3 para obter o LD e por 10 para obter o LQ. ${ }^{11}$

A precisão foi expressa em termos de repetitividade e precisão intermediária. Para determinar a repetitividade, as amostras foram fortificadas em seis replicatas e em três concentrações $(250,500$ e $\left.750 \mu \mathrm{g} \mathrm{kg}^{-1}\right)$. Para determinar a precisão intermediária, as amostras foram fortificadas em seis replicatas, em três concentrações (250, 500 e $750 \mu \mathrm{g} \mathrm{kg}^{-1}$ ) e em três dias consecutivos. Os resultados foram expressos pelo coeficiente de variação.

A exatidão foi determinada a partir de ensaios de recuperação em que quantidades conhecidas de analito foram adicionadas à amostra em seis replicatas de três concentrações diferentes $(250,500$ e $750 \mu \mathrm{g}$ $\mathrm{kg}^{-1}$ ). Os resultados foram expressos em porcentagem de recuperação.

\section{Avaliação da dissipação de difenoconazol em morango após múltiplas aplicações}

O experimento foi conduzido em casa de vegetação empregando 40 vasos (3,0 L de capacidade) contendo quatro plantas de morango por vaso. A irrigação foi feita diretamente no solo, duas vezes por semana. O produto comercial do fungicida difenoconazol $\left(250 \mathrm{~g} \mathrm{~L}^{-1}\right)$ foi pulverizado nas folhas, na dosagem recomendada para o produto utilizado (40 $\mathrm{mL} \mathrm{ha}^{-1}$ ) três dias antes da primeira colheita dos frutos. Esse produto comercial pode ser aplicado até seis vezes na cultura do morango, com intervalos de 14 dias entre as aplicações. ${ }^{1}$ Em função disso, foram feitas seis aplicações com o produto comercial, respeitando o intervalo de 14 dias entre cada tratamento. As amostras de morango foram coletadas no $3^{\circ}$ e $7^{\circ}$ dia depois de cada aplicação, totalizando 77 dias de monitoramento. Depois de colhidos, os frutos foram transportados para o laboratório, onde foram triturados em mixer e armazenados em freezer. Essas amostras foram submetidas ao método de extração ESL/PBT e os extratos foram analisados por CG/DCE.

\section{RESULTADOS E DISCUSSÃO}

\section{Otimização dos parâmetros de extração}

A eficiência da extração sólido-líquido com partição em baixa temperatura (ESL/PBT) pode sofrer a influência de alguns fatores como a escolha da solução extratora, tempos de agitação, de centrifugação e de refrigeração e da razão massa de amostra/volume de solução extratora. A escolha correta do melhor conjunto de parâmetros de trabalho leva à maior frequência analítica (maior número de análise por unidade de tempo), boa sensibilidade e precisão.

Para avaliar as melhores condições de extração, um planejamento fatorial completo $2^{2}$ foi empregado. Nesse planejamento, as variáveis solução extratora (acetonitrila ou uma mistura de acetonitrila:acetato de etila - 81,25:18,75 v/v) e a razão massa de amostra:volume de solução extratora foram avaliadas. Na Figura 2 é apresentado o gráfico de Pareto para os efeitos desses fatores sobre a extração do difenoconazol.

Pela análise dos efeitos dos fatores sobre a resposta cromatográfica do difenoconazol verificou-se que o fator solução extratora não apresentou efeito principal significativo ao nível de $95 \%$ de confiança $(\mathrm{p}<0,05)$. Isto é, diminuir a polaridade com a adição de acetato de etila à solução extratora não interferiu significativamente no método. Já a proporção massa de amostra/volume de solução extratora no nível mais baixo (4,0 g:4,0 mL) apresentou efeito significativo, melhorando a resposta cromatográfica do difenoconazol. Deste modo, optou-se pelo uso de 4,0 mL de acetonitrila como solvente extrator e $4,0 \mathrm{~g}$ de amostra.

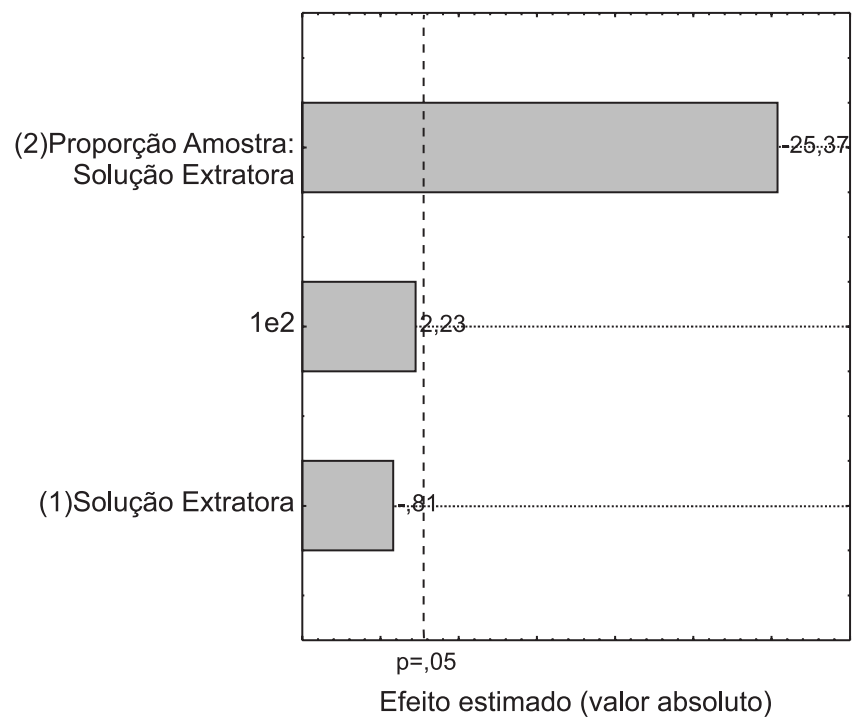

Figura 2. Diagrama de Pareto dos efeitos dos fatores solução extratora e razão amostra:solução extratora sobre a extração do difenoconazol de amostras de morango

A otimização dos tempos de agitação, centrifugação e refrigeração, tendo como resposta a área cromatográfica, foi realizada de acordo com planejamento fatorial completo $2^{3}$ com cinco repetições no ponto central e extensão axial (composto central). Na Figura 3 é apresentado o gráfico de Pareto para os efeitos dos fatores: tempos de agitação, centrifugação e refrigeração sobre a extração do difenoconazol.

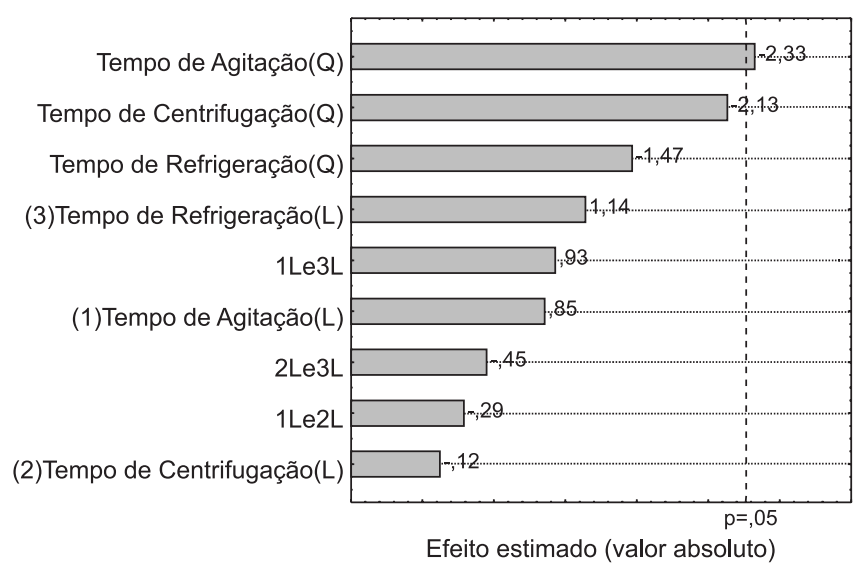

Figura 3. Diagrama de Pareto dos efeitos dos fatores tempos de agitação, centrifugação e refrigeração sobre a extração do difenoconazol de amostras de morango

Pela análise dos efeitos dos fatores sobre os agrotóxicos verificou-se que apenas o fator tempo de agitação foi significativo ao nível de $95 \%$ de confiança $(\mathrm{p}<0,05)$. Pelos valores críticos, as melhores condições experimentais foram: $17 \mathrm{~min}$ de agitação (200 rpm), $4 \mathrm{~min}$ de centrifugação $(560 \mathrm{~g})$ e $10 \mathrm{~h}$ de refrigeração $\left(\sim-20^{\circ} \mathrm{C}\right)$.

Levando-se em consideração os resultados da otimização e aspectos práticos da técnica, o método de ESL/PBT consiste em adicionar a 4,0000 $\mathrm{g}$ de amostra de morango 4,0 $\mathrm{mL}$ de acetonitrila. Essa mistura é agitada por $17 \mathrm{~min}$ em mesa agitadora, a $25^{\circ} \mathrm{C}$ e $200 \mathrm{rpm}$ e posteriormente centrifugada por $4 \mathrm{~min}$ a $560 \mathrm{~g}$ e deixada resfriar em freezer a aproximadamente $-20{ }^{\circ} \mathrm{C}$ por $10 \mathrm{~h}$. Do extrato sobrenadante retira-se $1,8 \mathrm{~mL}$ para análise cromatográfica.

A técnica ESL/PBT otimizada apresenta baixo consumo de 
amostra e de solvente extrator, não sendo necessário implementar etapas de evaporação e troca de solvente, o que reduz os riscos de contaminação e perdas de amostras.

\section{Validação do procedimento analítico}

Para avaliar a seletividade, o método otimizado foi aplicado em frutos de morango isentos de agrotóxicos. Posteriormente, essas amostras foram fortificadas com difenoconazol e submetidas novamente ao método de extração e análise. Os cromatogramas referentes a essas amostras foram comparados, não sendo observado nenhum interferente com resposta no tempo de retenção do analito de interesse (Figura 4). O pico duplo observado no cromatograma corresponde aos isômeros estruturais do difenoconazol.

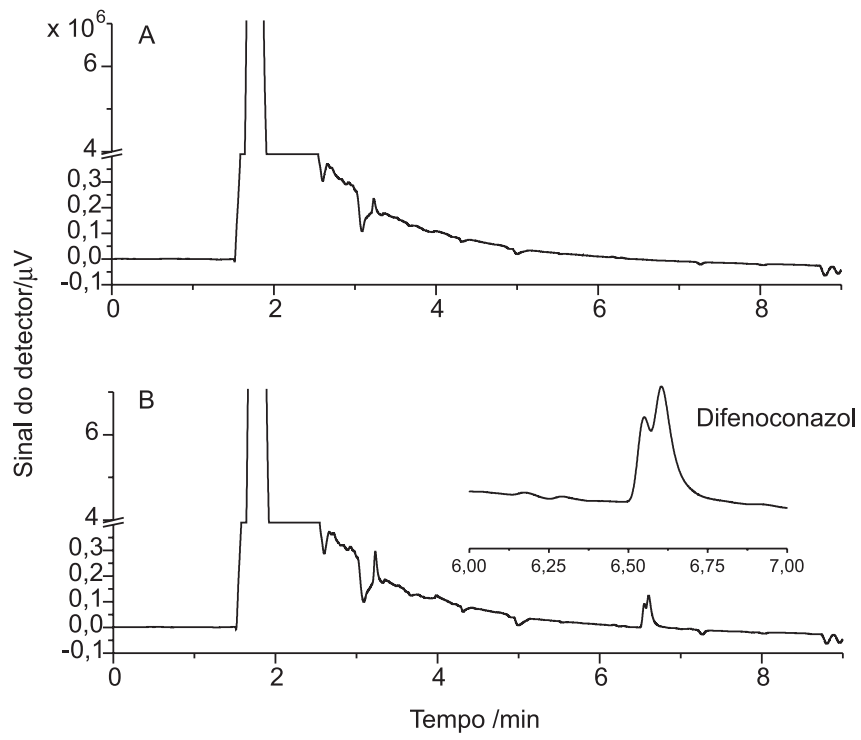

Figura 4. Cromatogramas de extratos obtidos de amostras de morango (A) isenta de difenoconazol; (B) contendo difenoconazol a $0,5 \mathrm{mg} \mathrm{kg}^{-1} \mathrm{com}_{R}=$ 6,60 min. Em destaque o pico duplo referente aos isômeros estruturais do difenoconazol

Para avaliar a linearidade do método, foi obtida a equação da curva analítica, com sete pontos, por meio de regressão linear $(\mathrm{y}=$ $697660 \mathrm{x}+10180)$ no intervalo entre 250 e $1000 \mu \mathrm{g} \mathrm{kg}^{-1}$ na matriz. $\mathrm{O}$ coeficiente de correlação (r) obtido foi de 0,995 . Esse valor indica a boa linearidade de resposta do método para o difenoconazol em concentrações próximas ao LMR. ${ }^{13}$ Para verificar se o ajuste linear foi adequado à curva analítica, plotou-se o gráfico de resíduos e aplicou-se o teste de Cochran dos dados. Os valores de Cochran calculados foram inferiores ao valor de Cochran tabelado, mostrando variâncias homogêneas conforme o aumento da concentração. A variância dos erros foi constante no intervalo de concentração estudado, sendo os resíduos distribuídos aleatoriamente em torno do zero. Este resultado indica que, na faixa de concentração estudada, o modelo tem um comportamento homocedástico.

Os limites de detecção (LD) e quantificação (LQ) do método estimados pelos parâmetros da curva analítica foram 9 e $31 \mu \mathrm{g} \mathrm{kg}^{-1}$, respectivamente. O LQ obtido está bem abaixo dos LMRs estabelecidos pela Agência de Vigilância Sanitária Brasileira (ANVISA, 500 $\mu \mathrm{g} \mathrm{kg}{ }^{-1}$ ) e pela União Europeia (EU, $400 \mu \mathrm{g} \mathrm{kg}^{-1}$ ).

A repetitividade foi avaliada em três níveis de concentração (250, 500 e $750 \mu \mathrm{g} \mathrm{kg}^{-1}$ ), sendo os valores obtidos de coeficiente de variação (CV) iguais a 11,$69 ; 5,89 ; 6,99 \%$, respectivamente. A precisão intermediária também foi avaliada pelo valor do CV dos dados de análises realizadas em três dias consecutivos. Em cada ensaio seis amostras fortificadas com difenoconazol, em cada nível de concentração (250, $500 \mathrm{e} 750 \mu \mathrm{g} \mathrm{kg}^{-1}$ ) foram analisadas por um mesmo analista, no mesmo laboratório, sob as mesmas condições de trabalho. Os valores de CV obtidos foram de 15,49; 9,57 e 8,21\%, respectivamente.

As recuperações foram $98 \pm 12 \%\left(250 \mu \mathrm{g} \mathrm{kg}^{-1}\right), 109 \pm 6 \%$ (500 $\left.\mu \mathrm{g} \mathrm{kg}{ }^{-1}\right)$ e $103 \pm 7 \%\left(750 \mu \mathrm{g} \mathrm{kg}^{-1}\right)$. Para a análise de resíduos de agrotóxicos o procedimento analítico deve ser capaz de recuperar, em cada nível de fortificação, de 70 a $120 \%$ em média, com uma precisão espressa em termos de $\mathrm{CV} \leq 20 \% .{ }^{14}$ Uma vez que os valores obtidos estão dentro deste intervalo, pode-se concluir que a recuperação e o coeficiente de variação para difenoconazol são adequados.

\section{Avaliação da dissipação de difenoconazol em morango após múltiplas aplicações}

A ESL/PBT vem sendo utilizada para extração de diversos agrotóxicos em diferentes matrizes com resultados satisfatórios. ${ }^{9,10}$ Além de promover uma extração eficiente dos analitos, a técnica tem a vantagem de realizar simultaneamente os processos de extração e clean-up.

Alguns autores descrevem a dissipação de agrotóxicos em diferentes matrizes, entretanto não mostram o efeito de aplicações sucessivas sobre a dissipação dos mesmos. ${ }^{15-20}$

A ESL/PBT foi aplicada para avaliar a dissipação do fungicida sistêmico difenoconazol em morangos durante seis aplicações sucessivas do produto comercial. As concentrações residuais de difenoconazol determinadas, em triplicata, durante os seis tratamentos nos diferentes dias são apresentadas na Figura 5.

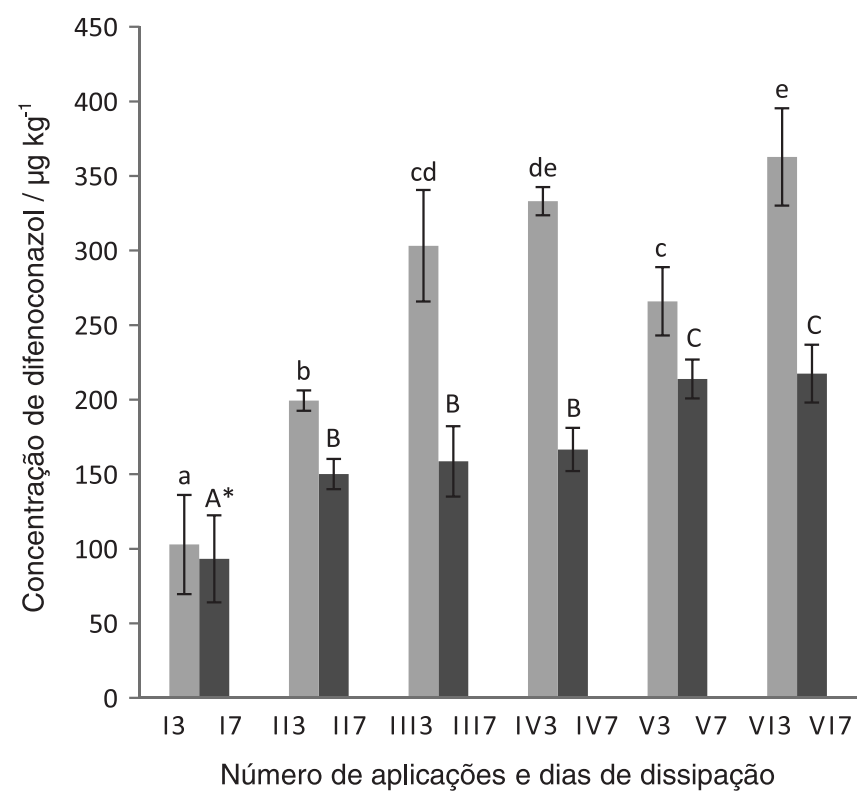

Figura 5. Concentrações residuais de difenoconazol em morangos depois de múltiplas aplicações. Algarismos romanos (I a VI) representam as seis aplicações e algarismos arábicos ( 3 e 7) os números de dias após a aplicação. Letras iguais não diferem entre si no teste ANOVA com post-hoc teste de Tukey ( $p<0,05)$; *: diferença não significativa entre as duas colheitas de uma mesma aplicação

As aplicações sucessivas do produto comercial contendo o difenoconazol levaram a um aumento das concentrações residuais desse princípio ativo nos morangos, avaliadas no terceiro dia depois de cada aplicação (3). Comportamento semelhante é observado nos resultados obtidos no sétimo dia depois de cada aplicação (7). Entretanto, esses 
resultados são significativamente menores do que os obtidos para o terceiro dia (3) a partir da segunda aplicação (II), mostrando que ocorre a dissipação do produto nesse período.

Wang et al. ${ }^{5}$ monitoraram a dissipação do difenoconazol em couve chinesa e mostraram que este se dissipa rapidamente com meia-vida de 6,6-7,8 dias. Mukhopadhyay et al. ${ }^{21}$ mostraram que a meia-vida de difenoconazol em pimentões é ainda menor, cerca de 2,15-2,32 dias. Sendo assim, não se esperava encontrar, nos morangos, resíduos de difenoconazol remanescente de uma aplicação para outra, já que o intervalo entre as aplicações foi de 14 dias. No entanto, depois das seis aplicações sucessivas do difenoconazol, observou-se um aumento nos níveis de agrotóxico no fruto. Os resíduos de difenoconazol observados nos frutos colhidos no terceiro dia (3) e no sétimo dia (7) depois da primeira aplicação (I); (I3 $=102,9 \mu \mathrm{g} \mathrm{kg}^{-1}$ e I7 $=93,3$ $\mu \mathrm{g} \mathrm{kg}^{-1}$ ) são significativamente inferiores aos observados nas colheitas seguintes. Depois da sexta aplicação (VI) foi encontrada para o terceiro dia (3) uma concentração residual (VI3 = 362,8 $\mu \mathrm{g} \mathrm{kg}^{-1}$ ) 3,5 vezes maior que a encontrada na primeira aplicação (I). Mesmo ocorrendo dissipação do fungicida, no sétimo dia (7) depois da sexta aplicação (VI) a concentração residual foi 2,3 vezes maior que a da primeira aplicação (I); (VI7 = 217,5 $\left.\mu \mathrm{g} \mathrm{kg}^{-1}\right)$.

\section{CONCLUSÕES}

O método de ESL/PBT e análise por cromatografia gasosa, otimizado e validado é simples e eficiente, consumindo uma pequena quantidade de amostra e de solvente extrator, com porcentagens de recuperação elevadas e boa repetitividade.

Os resultados mostraram que o difenoconazol aplicado em morangos dissipa rapidamente, mas que com múltiplas aplicações a concentração residual aumenta devido à persistência do produto.

\section{AGRADECIMENTOS}

Ao Conselho Nacional de Desenvolvimento Científico e Tecnológico (CNPq), à Fundação de Amparo à Pesquisa do Estado de Minas Gerais (FAPEMIG) e à Coordenação de Aperfeiçoamento de Pessoal de Nível Superior (CAPES) pelo apoio financeiro.

\section{REFERÊNCIAS}

1. Barbosa, C. A., Compêndio de defensivos agrícolas. AgroJuris: Viçosa, 2010.

2. Jardim, A. N. O.; Caldas, E. D.; Food Control 2012, 25, 607.

3. http://portal.anvisa.gov.br, acessada em Fevereiro 2012.

4. Oshita, D.; Jardim, I. C. S. F.; Scientia Chromatographica 2012, 4, 52.

5. Wang, Z. H.; Yang, T.; Qin, D. M.; Gong, Y.; Ji, Y.; Chin. Chem. Lett. 2008, 19, 969.

6. Schermerhorn, P. G.; Golden, P. E.; Krynitsky, A. J.; Leimkuehler, W. M.; J. AOAC Int. 2005, 88, 1491.

7. El Mouden, O. I.; Zougagh, M.; Lemerhyeratte, A.; Salghi, R.; Bazzi, L.; Hormatallah, A.; Chakir, A.; Riosi, A.; Ital. J. Food Sci. 2009, 21, 517.

8. Vieira, H. P.; Neves, A. A.; Queiroz, M. E. L. R.; Quim. Nova 2007, 30, 535.

9. Pinho, G. P.; Neves, A. A.; Queiroz, M. E. L. R.; Silvério, F. O.; Food Chem. 2010, 121, 251.

10. Marthe, D. B.; Bittencourt, L. M.; Queiroz, M. E. L. R.; Neves, A. A.; Quim. Nova 2010, 33, 1389.

11. Ribani, M.; Bottoli, C. B. G.; Collins, C. H.; Jardim, I. C. S. F.; Melo, L. F. C.; Quim. Nova 2004, 27, 771.

12. Goulart, S. M.; Queiroz, M. E. L. R.; Neves, A. A.; Queiroz, J. H.; Talanta 2008, 75, 1320.

13. INMETRO, INSTITUTO NACIONAL DE METROLOGIA, NORMALIZAÇÃO E QUALIDADE INDUSTRIAL. DOQ-CGCRE-008: Orientação sobre validação de métodos de ensaios químicos. INMETRO: Rio de Janeiro, 2010.

14. Brasil, Ministério da Agricultura Pecuária e Abastecimento. Manual de garantia da qualidade analítica. MAPA/ACS: Brasília, 2011.

15. Geng, Y.; Jia, R.; Li, C.; Ma, X.; Lin, Y.; Bull. Environ. Contam. Toxicol. 2012, 89, 669 .

16. Wu, Y.; Liu, X.; Dong, F.; Xu, J.; Zheng, Y.; Bull. Environ. Contam. Toxicol. 2012, 89, 1264.

17. You, X.; Jiang, N.; Liu, F.; Liu, C.; Wang, S.; Bull. Environ. Contam. Toxicol. 2013, 90, 238.

18. Abd-Alrahman, S.; Ahmed, N.; Bull. Environ. Contam. Toxicol. 2013, 90, 260.

19. Sun, D.; Li, L.; Liang, H.; Li, W.; Ji, R.; Wu, Y.; Liu, C.; Environ. Monit. Assess. 2012, 184, 5743.

20. Malhat, F. M.; Mahmoud, H. A.; ISRN Anal. Chem. 2012, 2012, 1.

21. Mukhopadhyay, S.; Das, S.; Bhattacharyya, A.; Pal, S.; Bull. Environ. Contam. Toxicol. 2011, 87, 54. 